\title{
Pengaturan Mass-Spring-Damper menggunakan Kontroler PI dan Fuzzy
}

\author{
Krisna Warih Bintang Pamungkas*1, Bayu Fandidarma ${ }^{2}$ \\ ${ }^{1,2}$ Universitas PGRI Madiun, Indonesia, Fakultas Teknik, Prodi Teknik Elektro \\ e-mail: *1compaq260616@gmail.com, ${ }^{2}$ bayuf@ unipma.ac.id
}

\begin{abstract}
Abstrak
Penelitian ini dilakukan dengan tujuan mengajarkan kepada mahasiswa supaya dapat melakukan pengaturan pada suatu sistem mass-spring-damper (MSD) nonlinier dengan cara yang lebih mudah yaitu menggunakan metode linierisasi pada sistem tersebut. Sistem MSD yang telah dilinierisasi untuk selanjutnya akan disimulasikan pada Simulink MatLab dengan menggunakan kontroler PI dan Fuzzy untuk mengatur posisi benda $m$ pada sistem supaya sesuai dengan set-point yang diinginkan. Pengujian dilakukan berdasarkan dua kontroler yang dipakai. Selanjutnya kedua hasil pengujian dibandingkan dan dianalisa. Kontroler PI berhasil menghasilkan respon yang lebih baik dibandingkan respon dari kontroler Fuzzy. Hal ini dikarenakan kontroler PI yang cocok dipakai pada sistem yang simpel dan linier. Sedangkan kontroler Fuzzy lebih cocok untuk sistem yang lebih kompleks dan nonlinier.
\end{abstract}

Kata kunci - fuzzy, kontroler PI, linier, mamdani, mass-spring-damper

\begin{abstract}
This research was conducted with the aim of teaching students to do some control for a nonlinear mass-spring-damper (MSD) system in an easier way, namely by using the linearization method for the system. The linearized MSD system will then be simulated on the MatLab Simulink using PI and Fuzzy controllers to adjust the position of object $m$ in the system so that it matches the desired set-point. The experiment is carried out based on the two controllers used. Furthermore, the two test results are compared and analyzed. PI controller managed to produce a better response than the response from the Fuzzy controller. This is because the PI controller is suitable for use in simple and linear systems. Meanwhile, Fuzzy controllers are more suitable for more complex and nonlinear systems.
\end{abstract}

Keywords - fuzzy, linear, mamdani, mass-spring-damper, PI controller

\section{PENDAHULUAN}

Perkembangan teknologi Mass-Spring-Damper (MSD) sangat berguna untuk berbagai macam lini kehidupan dan industri. Salah satu lini industri yang menggunakan teknologi MSD ini adalah lini mesin beroda (sepeda motor, mobil, bus, truk dan lain sebagainya). Karenanya perlu dilakukan penelitian yang fokus dan merata pada teknologi MSD tersebut. Alangkah baiknya jika penelitian tersebut sudah mulai dapat diteliti mahasiswa yang notabene-nya belum pernah menulis buku. Sehingga perlu diturunkan sampai level mahasiswa dan dalam bentuk linier. 
Sistem MSD nonlinier yang dikontrol menggunakan springed-piston sudah diteliti dengan mengunakan kontroler LQR dan Fuzzy-Mamdani [1]. Jadi sistem MSD memiliki spring dengan sifat hardened sehingga sistem MSD menjadi nonlinier. Lalu untuk keluaran kendalinya diberikan pada springed-piston.

Penelitian selanjutnya berupa pengaturan posisi dari sistem MSD yang dicoupled menggunakan Simulink dan Simelectronics [2]; pengaturan sistem MSD menggunakan kontroler adaptif PI [3]; perbandingan analisa pemakaian kontroler P, PI, PD dan PID pada sistem MSD menggunakan MatLab Simulink [4]; desain pengaturan sistem MSD berdasarkan skema kendali backstepping [5]; dan penggunaan kontroler PI pada alat Pasteurisasi [6] menjadi acuan penggunaan kontroler PI pada penelitian kali ini.

Sistem MSD dari penelitian [1] diambil untuk dilinierisasikan supaya lebih mudah untuk dilakukan simulasi dengan menggunakan kontroler PI dan FuzzyMamdani pada Simulink MatLab. Hasil respon keduanya akan dibandingkan dan dianalisa untuk menentukan kontroler terbaik.

Artikel ini disusun berdasarkan urutan sebagai berikut. Metode Penelitian dijelaskan pada bab 2. Hasil dan Pembahasan dipresentasikan pada bab 3. Bab 4 berisikan Kesimpulan akhir dari penelitian yang telah dilaksanakan.

\section{METODE PENELITIAN}

Pada bagian ini, metode penelitian dijabarkan berdasarkan dasar teori dan fungsi yang diinginkan untuk merumuskan hasil penelitian dan selanjutnya dianalisa untuk diambil kesimpulannya.

\section{Pemodelan Sistem Linearized-Mass-Spring-Damper}

Pada bagian ini, metode penelitian dijabarkan berdasarkan dasar teori dan fungsi yang diinginkan untuk merumuskan hasil penelitian dan selanjutnya dianalisa untuk diambil kesimpulannya.

Sistem Mass-Spring-Damper (MSD) yang dipergunakan dalam penelitian kali ini mengacu pada sistem MSD Nonlinier yang dikontrol oleh Springed-Piston [1]. Sistem ini akan dilinierisasikan (Linearized) dengan asumsi bahwa pegas yang dipakai adalah pegas linier sehingga konstanta hardening $\alpha$ adalah nol, maka persamaan dinamika sistem berubah menjadi sebagai berikut

$$
\begin{aligned}
& k y+\beta v+u=m a \\
& k y+\beta \dot{y}+u=m \ddot{y} \\
& m \ddot{y}-\beta \dot{y}-k y=u
\end{aligned}
$$

Selanjutnya melakukan penyusunan bentuk state-space sistem untuk melakukan simulasi di MatLab. Jika $x_{1}=y$ dan $x_{2}=\dot{y}$, maka

$$
\begin{gathered}
\dot{x}_{1}=\dot{y}=x_{2} \\
\dot{x}_{2}=\ddot{y}=\frac{k}{m} y+\frac{\beta}{m} \dot{y}+\frac{1}{m} u=\frac{k}{m} x_{1}+\frac{\beta}{m} x_{2}+\frac{1}{m} u \\
{\left[\begin{array}{l}
\dot{x}_{1} \\
\dot{x}_{2}
\end{array}\right]=\left[\begin{array}{ll}
0 & 1 \\
\frac{k}{m} & \frac{\beta}{m}
\end{array}\right]\left[\begin{array}{l}
x_{1} \\
x_{2}
\end{array}\right]+\left[\begin{array}{l}
0 \\
\frac{1}{m}
\end{array}\right] u}
\end{gathered}
$$




$$
\begin{gathered}
{\left[\begin{array}{l}
\dot{y} \\
\dot{y}
\end{array}\right]=\left[\begin{array}{ll}
0 & 1 \\
\frac{k}{m} & \frac{\beta}{m}
\end{array}\right]\left[\begin{array}{l}
y \\
\dot{y}
\end{array}\right]+\left[\begin{array}{l}
0 \\
\frac{1}{m}
\end{array}\right] u} \\
z=\left[\begin{array}{ll}
1 & 0
\end{array}\right]\left[\begin{array}{l}
y \\
\dot{y}
\end{array}\right]
\end{gathered}
$$

\section{Kontroler Proportional-Integral (PI)}

Kontroler Proportional-Integral (PI) adalah kontroler mekanisme umpan balik dengan menghitung secara proportional (P) dan integral (I) respon suatu sistem dengan tujuan untuk mengatur sistem supaya memenuhi suatu tujuan tertentu. Dalam sistem MSD ini menggunakan kontroler PI untuk mengatur posisi benda ${ }^{m}$ supaya sesuai dengan set-point yang diinginkan. Dari persamaan (7) dan (8) dibangunlah model untuk melakukan simulasi menggunakan kontroller PI pada MatLab/Simulink seperti yang ditunjukkan pada Gambar 1.

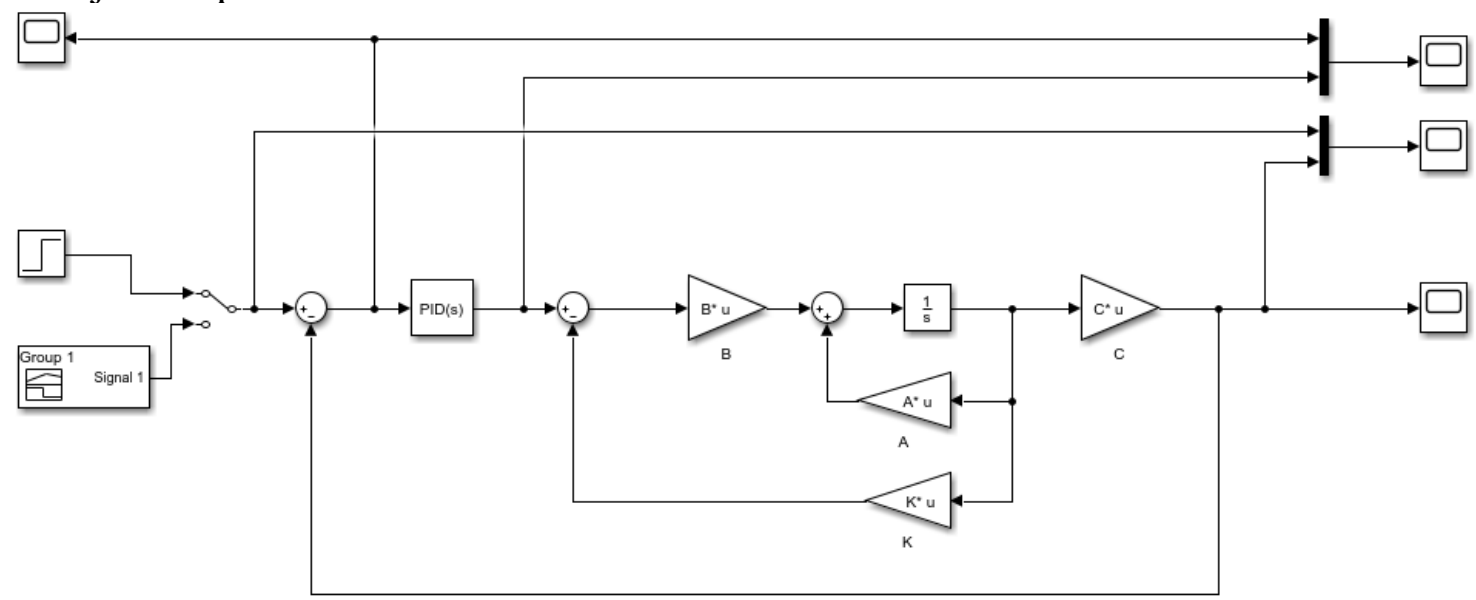

\section{Gambar 1 Model Sistem MSD menggunakan kontroler PI}

\section{Kontroler Fuzzy-Mamdani}

Kontroler Fuzzy yang digunakan dalam penelitian ini adalah kontroler fuzzy tipe mamdani. Kontroler ini akan digunakan untuk mengatur posisi benda ${ }^{m}$ sesuai dengan set-point yang sudah ditentukan. Dari persamaan (7) dan (8) dibangunlah model untuk melakukan simulasi menggunakan kontroller fuzzy-mamdani pada MatLab/Simulink seperti yang ditunjukkan pada Gambar 2.

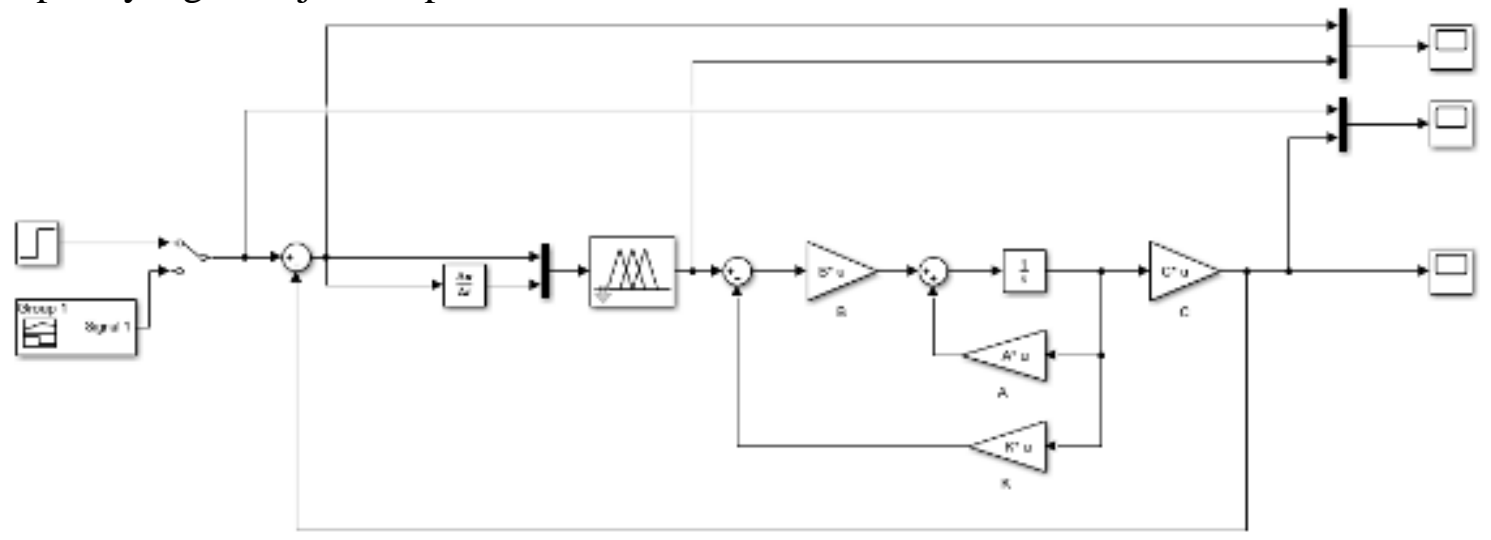

Gambar 2 Model Sistem MSD menggunakan kontroler Fuzzy-Mamdani 
Menyusun rule fuzzy untuk keperluan pengaturan fuzzy berikutnya sesuai dengan Tabel 1. Rule fuzzy menggunakan dua masukan yaitu input error dan input perror dan satu keluaran berupa input kontrol pada Piston. Variabel masukan yang dipakai adalah error $=$ referensi $\left(y_{r}\right)-$ posisi aktual $(y)$ dan perror $=$ derivative error terhadap waktu $\left(\frac{d\left(y_{r}-y\right)}{d t}\right)$.

Tabel 1 Rule Fuzzy Mamdani

\begin{tabular}{|l|l|l|c|c|}
\hline \multicolumn{2}{|c|}{ Output (u) } & \multicolumn{3}{c|}{ Error $\left(y_{r}-y\right)$} \\
\cline { 3 - 5 } & $\mathrm{N}$ & $\mathrm{Z}$ & $\mathrm{P}$ \\
\hline \multirow{3}{*}{ Perror $\left(\frac{d\left(y_{r}-y\right)}{d t}\right)$} & $\mathrm{N}$ & $\mathrm{N}$ & $\mathrm{Z}$ & $\mathrm{N}$ \\
\cline { 2 - 5 } & $\mathrm{Z}$ & $\mathrm{N}$ & $\mathrm{Z}$ & $\mathrm{P}$ \\
\cline { 2 - 5 } & $\mathrm{P}$ & $\mathrm{P}$ & $\mathrm{Z}$ & $\mathrm{P}$ \\
\hline
\end{tabular}

\section{HASIL DAN PEMBAHASAN}

Dalam simulasi pada MatLab menggunakan parameter-parameter berikut ini: konstanta spring $k=5 \mathrm{~kg} / \mathrm{s}^{2}$; konstanta damper $\beta=0.1 \mathrm{~kg} / \mathrm{s}$ dan massa benda $m=20$ $\mathrm{kg}$. Selanjutnya parameter-parameter tersebut dimasukkan pada bentuk state-space sistem (7) dan (8) sehingga menjadi seperti di bawah ini.

$$
\begin{gathered}
{\left[\begin{array}{l}
\dot{y} \\
\ddot{y}
\end{array}\right]=\left[\begin{array}{cc}
0 & 1 \\
0.25 & 0.005
\end{array}\right]\left[\begin{array}{l}
y \\
\dot{y}
\end{array}\right]+\left[\begin{array}{c}
0 \\
0.05
\end{array}\right] u} \\
z=\left[\begin{array}{ll}
1 & 0
\end{array}\right]\left[\begin{array}{l}
y \\
\dot{y}
\end{array}\right]
\end{gathered}
$$

Dengan menentukan set-point adalah +1 meter, posisi awal benda $m$ adalah 0 meter dan tujuan pengaturan adalah untuk benda $m$ dapat berpindah posisinya sesuai dengan set-point. Maka simulasi dilakukan pada MatLab/Simulink sesuai dengan kontroler dan parameter yang dipakai.

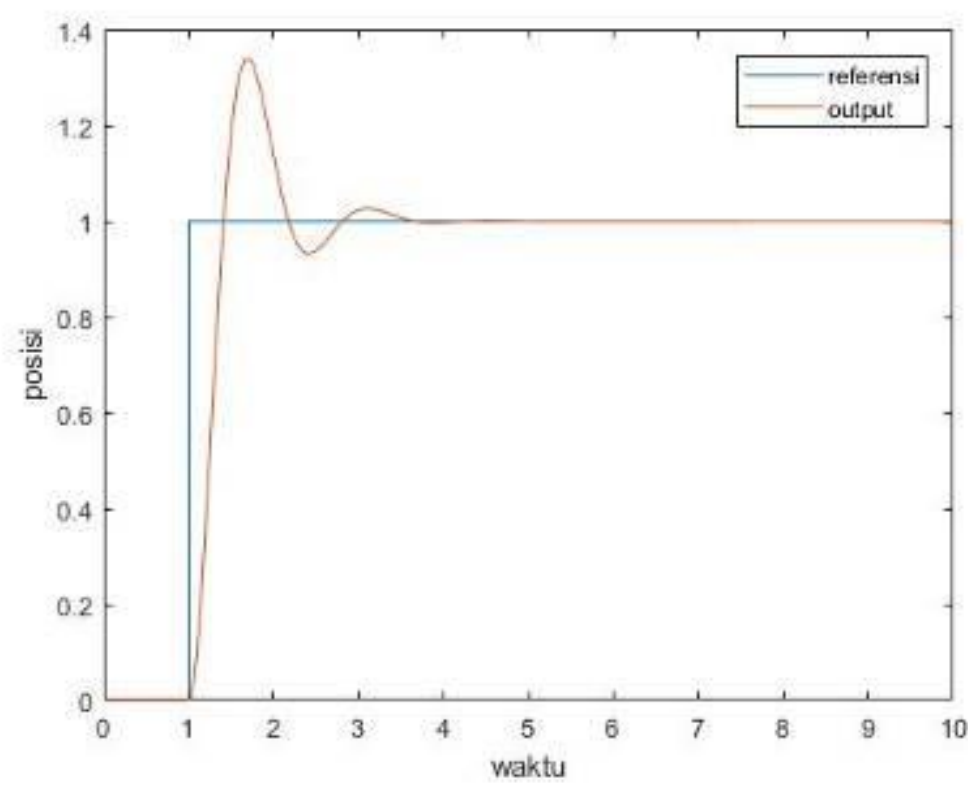

Gambar 3 Respon sistem MSD dengan kontroler PI 
Jurnal ELECTRA : Electrical Engineering Articles

Simulasi respon sistem MSD dengan kontroler PI yang ditunjukkan pada Gambar 3 dilaksanakan dengan menggunakan parameter gain $K=\left[\begin{array}{ll}10.0990 & 20.2239\end{array}\right]$, konstanta $\mathrm{P}=170.69$ dan konstanta $\mathrm{I}=52.62$.

Simulasi respon sistem MSD dengan kontroler Fuzzy-Mamdani yang ditunjukkan pada Gambar 5 dilaksanakan dengan menggunakan parameter fungsi keanggotaan pada dua masukan dan satu keluaran seperti yang ditunjukkan pada Gambar 4.a-c.

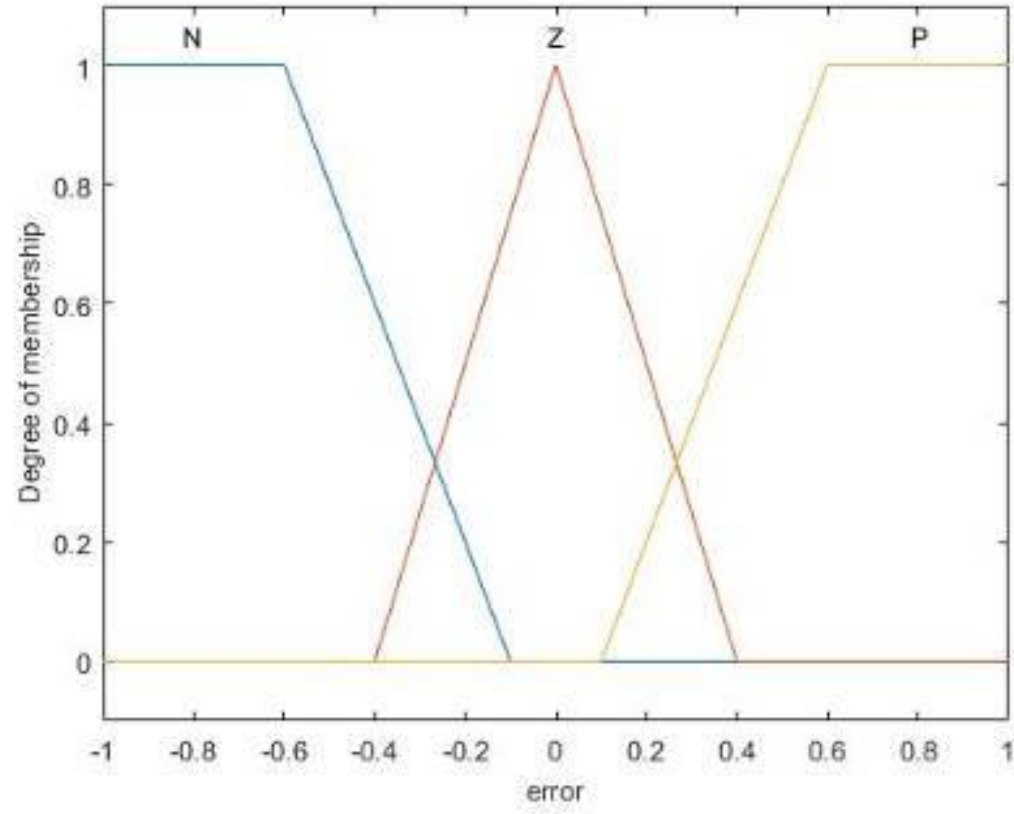

Gambar 4.a Fungsi Keanggotaan input error

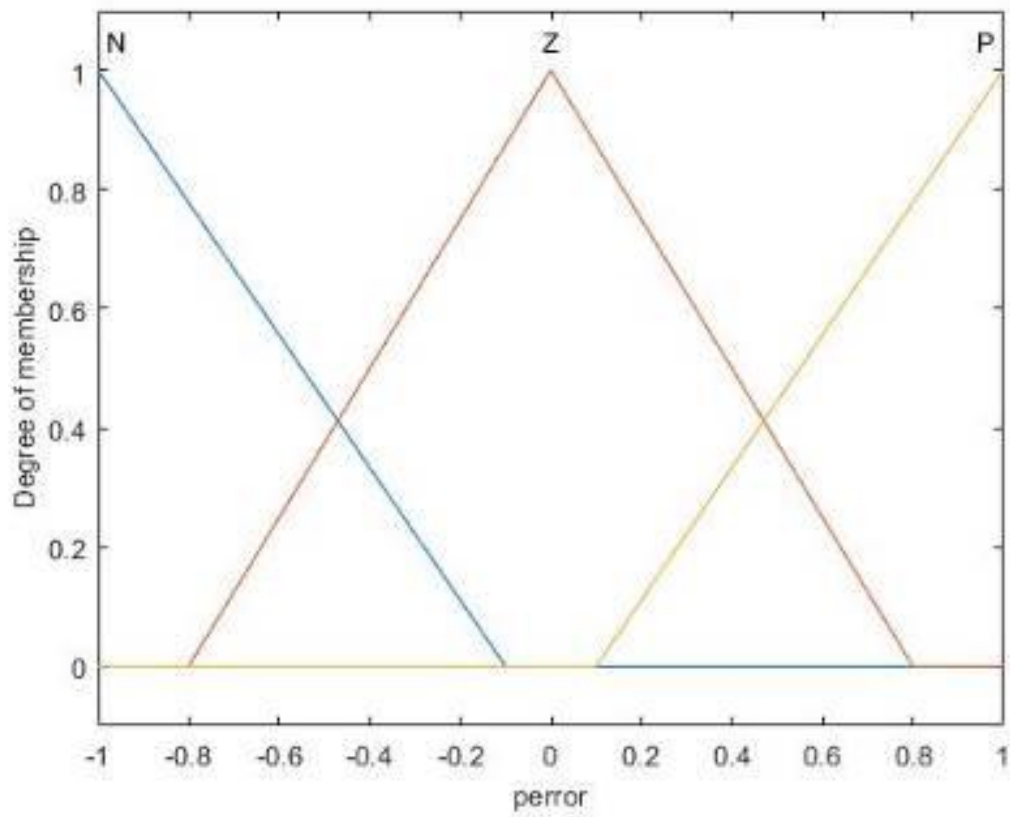

Gambar 4.b Fungsi Keanggotaan input perror 


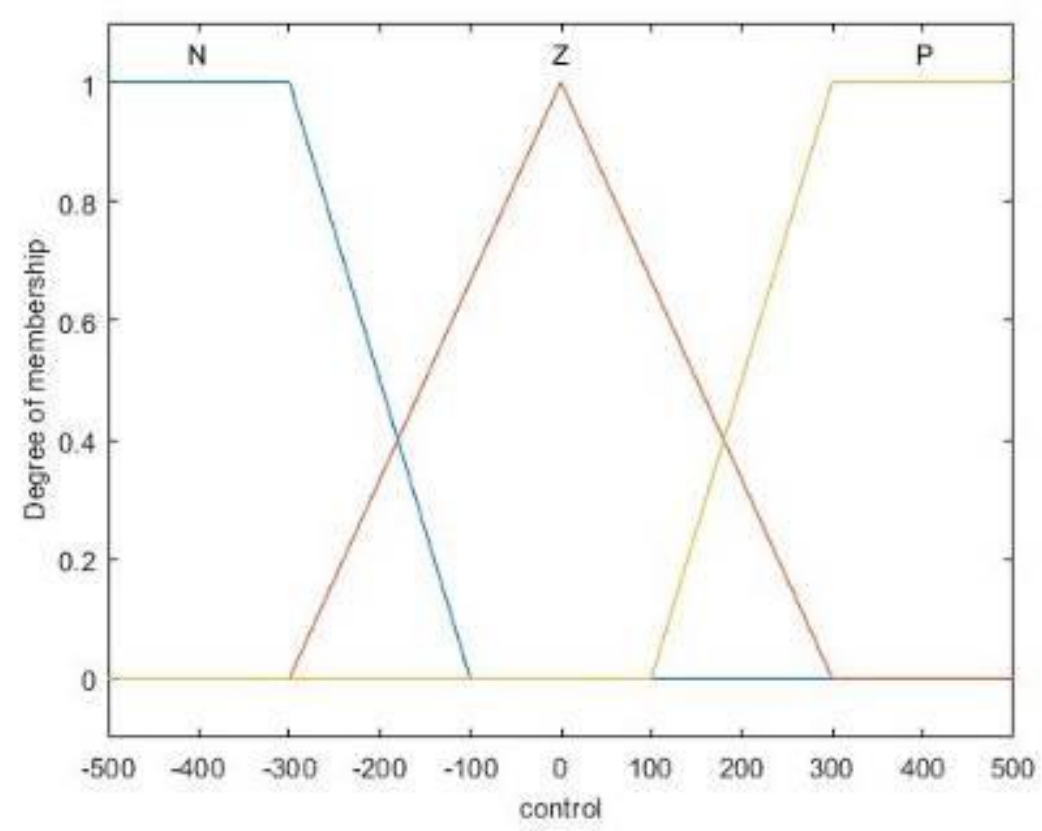

Gambar 4.c Fungsi Keanggotaan output u

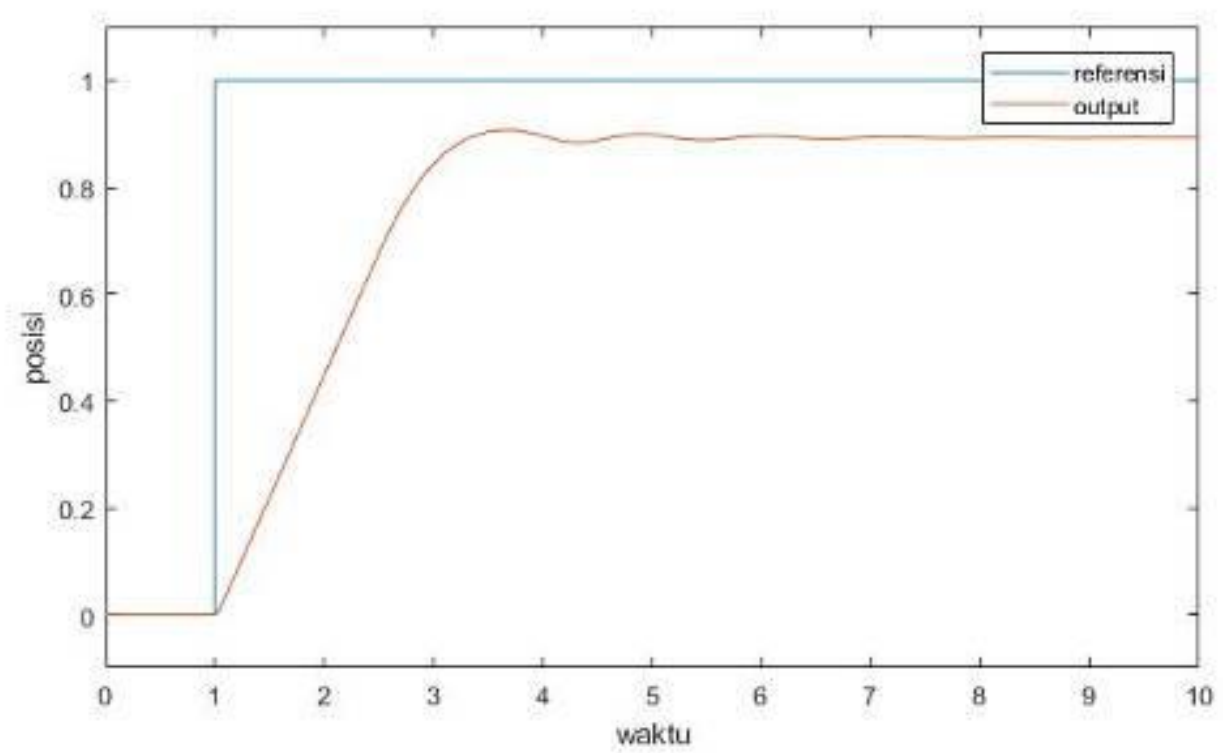

Gambar 5 Respon Sistem MSD dengan kontroler Fuzzy

Simulasi untuk kedua kontroler telah dilaksanakan. Terdapat perbedaan yang signifikan pada hasil respon antara keduanya. Hal ini menandakan adanya perbedaan kualitas dari penyusunan kontroler dan pemilihan parameter serta variabel yang digunakan. Kontroler PI menghasilkan respon posisi benda $m$ yang berhasil bergerak menuju posisi yang sesuai dengan set-point. Walaupun sedikit overshoot, tapi hal ini tidak berlangsung lama lalu posisi benda $m$ berangsur menuju set-point. Kontroler Fuzzy-Mamdani menghasilkan respon posisi benda ${ }^{m}$ yang cukup baik hanya saja posisi benda ${ }^{m}$ tidak sampai pada set-point yang diinginkan dan berisolasi setelahnya. 


\section{KESIMPULAN}

Setelah penelitian diuji dan dibahas, maka dapat ditarik kesimpulan yang diantaranya:

a. Hasil respon pada sistem MSD menggunakan kontroler PI sudah menunjukkan keberhasilan karena posisi benda ${ }^{m}$ sudah bergerak sesuai dengan set-point yang ditentukan. Walaupun sempat overshoot, tapi posisi benda ${ }^{m}$ kembali ke set-point.

b. Hasil respon pada sistem MSD menggunakan kontroler Fuzzy belum mnunjukkan keberhasilan karena posisi benda ${ }^{m}$ sudah bergerak tapi masih jauh dari set-point yang ditentukan dan berisolasi pada posisi itu sampai simulasi berhenti.

c. Kontroler PI dapat menghasilkan respon yang lebih baik (sesuai dengan set-point) dari kontroler Fuzzy karena kontroler PI mudah disusun dan penataan parameter dan variabelnya lebih simpel dan ringkas daripada kontroler Fuzzy.

d. Kontroler Fuzzy adalah kontroler yang lebih kompleks dan perlu menata banyak parameter dan variabel untuk mengatur suatu sistem. Keunggulan dari kontroler Fuzzy ini akan terlihat jika sistem yang dikendalikan semakin rumit.

\section{DAFTAR PUSTAKA}

[1] B. Fandidarma, C. Sari, and M.Y. Anshori, "Sistem regulator mass-spring-damper nonlinier yang dikontrol oleh springed-piston menggunakan LQR dan FLCMamdani," in $2^{\text {nd }}$ Seminar Nasional Teknologi Informasi dan Komunikasi (SENATIK), Madiun, 2019.

[2] A.A. Okubanjo, O.K. Oyetola, and O.O. Olaluwoye, "Simulink and simelectronics based position control of a coupled mass-spring damper mechanical system," in International Journal of Electrical and Computer Engineering (IJECE), vol. 8, no. 5, pp. 3636-3646, October 2018.

[3] S. Coman, and Cr. Boldisor, "Adaptive PI controller design to control a mass - damper - spring process," in Bulletin of the Transilvania University of Brasov, vol. 7 (56), no. 2, 2014.

[4] K. Ravindra, K. Yogesh, and G. Ankit, "Comparative analysis of P, PI, PD, PID controller for mass spring damper system using matlab simulink," in International Journal for Research in Engineering Application \& Management (IJREAM), Special Issue - ICRTET-2018, 2018.

[5] M.F. Badr, E.H. Karam, and N.M. Mjeed, "Control design of damper mass spring system based on backstepping controller scheme," in International Review of Applied Sciences and Engineering, Juli 2020.

[6] C. Sari, I.T. Yuniahastuti, and A. Putra, "Aplikasi kontroler PI modifikasi pada prototype alat pasteurisasi menggunakan simple water heater," in Jurnal ELEMENTER, vol. 6, no. 1, Mei 2020. 